\title{
A Better City: Geography of Power or Ecology of Responsibility?
}

\author{
JACEK DOMINICZAK \\ Carnegie Mellon University \\ USA
}

The paper discusses a design strategy based on the structure of responsibility. This structure generates the use of Hidden Compositional Codes for cities and the concept of a Dialogic Design -- ideas that are the subjects of reasearch projects developed in cooperation with undergraduate design studio participants. The papers concludes in a design method discussion about the possible shift from political solutions ruled by the geography of power that generate the conservative quality of a compromise, towards ethical definitions organized by the ecology of responsibility that may generate new, yet unknown, qualities.

Geography: An ordered arrangement of constituent elements

Ecology: The relationship between organisms and their environment

\section{- The American Heritage Dictionary}

To achieve professional status one must develop a concept of professional responsibility. In general, this responsibility addresses at least three issues:

- the Other -- through the ability-to-respond to his or her questions;

- knowledge -- through the ability to recognize his or her questions;

- response - through the ability to develop and to use successful strategies.

For an architectural discipline, each of these issues addresses the following aspects of the profession:

The Other. The ability-to-respond to a question of the Other makes us aware of the ethical primacy of those who request our work, before our own self-expression. The focus of the profession is therefore, in a specific readiness to cooperate -- with the client, or with other professionals!

Architectural Knowledge. The ability to recognize the question of knowledge ${ }^{2}$ makes us aware of how many are still unanswered. Here then, the focus of architectural knowledge is in continuous and specifically architectural re-search, rather than the use of a stable body of architectural or architecturally-related information.
Architectural Response. The ability to use successful strategies for a response makes us trustworthy for others and, hence, may generate an invitation to work together, to assist sin realizing omeone's dreams, or to cooperate with another's responsibilities.

\section{THE DESIGN STUDIO}

According to the explained principles, a Design Studio was conducted in the fifth year of the Architecture Program at Carnegie Mellon University during the past two semesters. This studio was a part of the Urban Laboratory Program which is intented ito build cooperation between architecture, public policy, and history students of Carnegie Mellon University ${ }^{3}$.

Since the studio addressed the problem of Urban Form and Reconstitution of the Inner-City Neighborhood, the issues of professional responsibility were formulated as follows:

- The participation in a multidisciplinary design process

- The use of specifically architectural information

- The application of an open design strategy

\section{The Other and a Multidisciplinary Design Process}

Architects' participation in a multidisciplinary discourse requires at least two major steps:

- precise preparation that includes recognition of the realm of a specifically architectural knowledge for which architects are solely responsible

- recognition of possible synergies between architectural knowledge and other realms of knowledge: especially those of social, economical, and political interest.

As a sole responsibility of architectural knowledge, the studio identified three major systems that shape the physical form of an urban environment:

- perceptual structure that allows one to understand the organization of the city form,

- visual composition that allows one to recognize spatial relations within urban interiors,

- behavioral appropriateness that allows one, personally and socially, to dwell in the urban space. 
As a potential synergy with the other professions, two qualitative goals were recognized:

- the value of Genius Loci of a place is understood as a positive continuation of both commonalties and uniqueness of the neighborhood

- the value of sustainability is understood as a preparation for continuity in changing situations ${ }^{4}$.

\section{Architectural Knowledge and an Urban Design Code}

In response to the recognized architectural systems and addressed values, three research project were developed:

- Perceptual information was gained through the analysis of The Hidden Compositional Code of the City that was developed during two years of research work conducted at Carnegie Mellon University by the author. Its final form was presented in the exhibition Uncovering Pittsburgh: Architectural Dialogues -- the joint effort of Jacek Dominiczak and Laura Lee 5 .

- Visual information was gained through typological analysis of urban interiors of the neighborhood.

- Behavioral data was gained through the typological interpretation of the material collected through site visits, interviews, and comparative studies.

As a result of a research, a specific urban design code was developed.

\section{A Response and the Dialogic Design Strategy}

The design strategy goal was defined as a continuation of a complex form of the North American urban environment with simultaneous use of a quality-controlling Urban Design Code. As a consequence of this goal, the studio focused on the application of a Dialogic Strategy of Design that addresses the antinomic relation between uncontrolled complexity and fully controlled difficult order, rather that the favoring of one. The essence of this strategy (which is the work in progress of the author) lies in the generation of a dialogue between two positive yet antinomic ideas that, through the very nature of antinomy, may create new and higher qualities rather than lowering standards through compromise. The structure of responsibility once again promotes a search for the ethical solution rather than a political one.

\section{CONCLUSION}

Contemplating the nature of a post-capitalist knowledgeoriented society one may find a relationship with the mechanism of architectural design. Peter F. Drucker ${ }^{6}$ writes about the necessity to focus our knowledge on problem definition rather than problem solving for the purpose of achieving a genuine connection between different knowledges. This, in an interesting way, parallels the possible shift from political solutions ruled by the geography of power that generate the conservative quality of a compromise, towards ethical definitions organized by the ecology of responsibility that may generate new, yet unknown, qualities.

\section{NOTES}

' Emmanuel Levinas: Totaite et Infini. Martinus Nijhoff, 1961

${ }^{2}$ Hans-Georg Gadamer: Wahrheitund Methode. J.C.B. Mohr, 1986

3 The program was coordinated by Professor David Lewis. Within the program independent design studios were conducted by the following Professors: Karen Brean, John Decker, Jacek Dominiczak, Stefani Ledewitz, David Lewis.

4 Peter Nijkamp, Adriaan Perrels: Sustainable Cities in Europe. Earthscan, 1994

${ }^{5}$ The exhibition was initially presented in The Hewlett Gallery, and in the AIA Gallery in Pittsburgh. Recently it was presented in Winnipeg, Canada.

6 Peter F. Drucker: Post-Capitalist Society. Harper Business, 1993 